Journal of Advanced Research in Fluid Mechanics and Thermal Sciences

\title{
Experimental Studies of Drying Pineapple with An Active Indirect Solar Tunnel Dryer in Malaysia
}

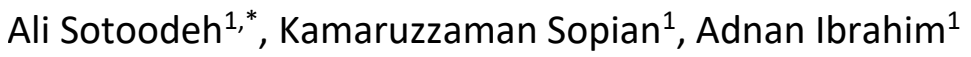 \\ 1 Solar Energy Research Institute (SERI), Universiti Kebangsaan Malaysia, 43600 UKM Bangi, Selangor, Malaysia
}

\begin{tabular}{|c|c|}
\hline ARTICLE INFO & ABSTRACT \\
\hline $\begin{array}{l}\text { Article history: } \\
\text { Received } 2 \text { December } 2020 \\
\text { Received in revised form } 14 \text { March } 2021 \\
\text { Accepted } 25 \text { March } 2021 \\
\text { Available online } 25 \text { May } 2021\end{array}$ & $\begin{array}{l}\text { Abundant sunshine and tropical climate of Malaysia have made pineapple a suitable } \\
\text { fruit to be grown in this country. However, to have longer shelf-life, lighter weight for } \\
\text { transportation and less storage space, drying of pineapple has been a common } \\
\text { preservation method in this country. Open-sun drying used to be most common } \\
\text { method of preserving agricultural products. Nevertheless, due to the disadvantages of } \\
\text { open sun drying method, solar drying technology has become an alternative method } \\
\text { of drying vegetables, fruits, spices, herbs etc. The main purpose of this paper is to } \\
\text { evaluate the performance of active solar tunnel dryer (ASTD) for drying sliced } \\
\text { pineapples. The air circulation system in this dryer is based on forced convection } \\
\text { system. In active solar tunnel dryer inlet airflow temperature was gained by } \\
\text { corrugated absorber plate. During the experiment minimum, maximum and average } \\
\text { of absorber thermal efficiency were } 13.1 \% \text { and } 24.4 \% \text {, and } 19.8 \% \text { respectively. The } \\
\text { inlet temperature range was between } 26^{\circ} \mathrm{C} \text { to } 38^{\circ} \mathrm{C} \text {, the escalated temperature range } \\
\text { was between } 34^{\circ} \mathrm{C} \text { to } 75^{\circ} \mathrm{C} \text { on the absorber outlet. Relative humidity (RH) experienced } \\
\text { changes due to irradiance intensity, the RH reduced when passed through the } \\
\text { absorber plate. The average inlet humidity was } 54 \% \text { while average outlet humidity }\end{array}$ \\
\hline Keywords: & was $36 \%$. During 9 hours of drying process, pineapple moisture content reduced from \\
\hline $\begin{array}{l}\text { Thermal Efficiency; Solar Tunnel Dryer; } \\
\text { Drying Pineapple; Solar Thermal energy }\end{array}$ & $\begin{array}{l}89 \% \text { to } 12.5 \% \text { and its weight decreased from } 5 \mathrm{~kg} \text { to } 0.62 \mathrm{~kg} \text {. The peak sun hours were } \\
5.7 \text { hours, and loading density was } 1.51 \mathrm{~kg} / \mathrm{m}^{2} \text {. }\end{array}$ \\
\hline
\end{tabular}

\section{Introduction}

About thirty percent of food products are lost or damaged globally, the wasting chain is from the producer to the consumer. Reducing postharvest losses (PHL) of agricultural products is one strategic method to escalate income [1]. Drying crops, which is defined as the process of moisture removal due to simultaneous heat and mass transfer, is the most common preservation method that has been used for decades. Drying agricultural products has several advantages such as longer shelf life, reduced mass and volume (convenience in transportation), access to wide range of products out of country of origin. Nonetheless, drying process is considered as a costly and energy intensive procedure, as it needs $10 \%$ to $15 \%$ of overall energy utilized in the industry [2]. Fossil fuel,

\footnotetext{
* Corresponding author.

E-mail address: ali.sotoodeh121@gmail.com
}

https://doi.org/10.37934/arfmts.83.1.105117 
natural gas, biomass, electricity, and solar thermal energy are common energy sources that are consumed for drying process. Solar energy can reduce fossil fuel cost up to $27 \%-80 \%$ for drying food products. The solar drying is known to be the inexpensive technique for drying and preserving food products. Using solar energy to dry agricultural products has become potentially a viable substitute for fossil fuel in countries where solar radiation is abundant [3-5]. Pineapple considers as one of the important local fruits of Malaysia has waste during harvest and shipping. Since the shelf life of fresh fruits is short, dried pineapple reserve duration is long.

\subsection{Solar Dryer Classification}

Proper design of solar dryers plays a key role in order to meet particular drying requirements of agricultural products. Various types of solar dryer have been designed and developed all over the world to optimize the drying process and reduce the operation cost. Figure 1 shows the classification of solar dryer. Solar dryer is mainly divided into open sun dryer (OSD) and controlled solar dryer [6]. The open sun dryer which is known to be one of the oldest, cheapest, and simplest type of dryer has several disadvantages [7]. According to Figure 1 the controlled solar dryer is classified into airflow convection mode, and exposure to insolation. Natural convection and forced convection are the two main types of airflow convection mode [8]. In natural mode there is no motor or fan while in forced convection system a blower or fan is an important component of the dryer. Exposure to insolation can be direct incident or indirect incident. In direct exposure to insolation, the load is directly exposed to solar radiation. For drying agricultural products which are sensitive to direct radiation, indirect drying system is a suitable alternative $[9,10]$.

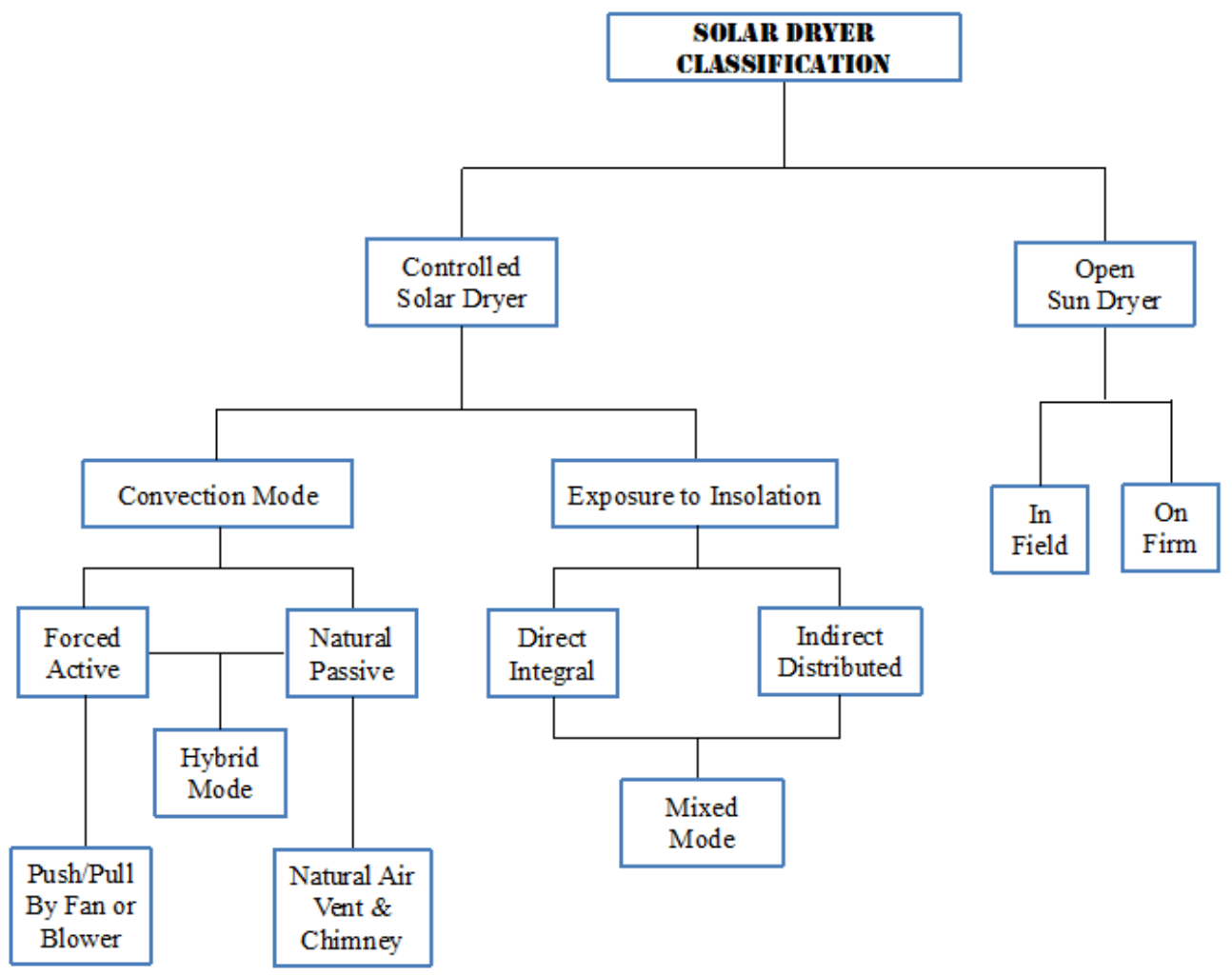

Fig. 1. Solar dryer classification 


\subsection{Solar Tunnel Dryer (STD)}

The solar tunnel drying system is used for drying a wide range of food grade and non-food grade of agricultural products. STD is convenient for transportation due to its small scale and is suitable for remote area. The semi-cylindrical shape of STD increases the radiation absorption and reduces reflection. The structure of STD is not complex and mainly consists of thermal absorber, crops trays, inlet and outlet air vent, and fan. The drying chamber is usually covered by the plastic sheets such as polycarbonate which is UV resistant or glasses [11]. In addition, the thermal collector element is generally in matt black color to maximize radiation absorption. Figure 2 and 3 demonstrate the solar tunnel dryer in different capacities and the main components of this type of dryer. Radiation incident on solar tunnel dryers is typically indirect and air convection system is active mode. Numerous experimental studies have proved that the use of the solar tunnel drier leads to considerable decrease of drying time in comparison to open sun drying [12]. As it illustrated in Figure 2 the collector can be placed before drying chamber for small scale dryers. However, for larger scale dryers, the collector is placed along the length of the dryer.

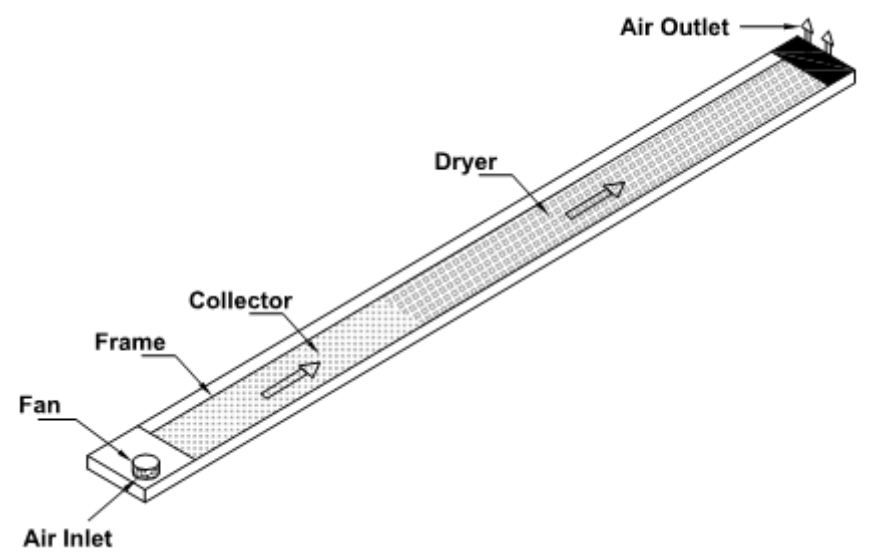

Fig. 2. Solar tunnel dryer for small quantities of agricultural products [13]

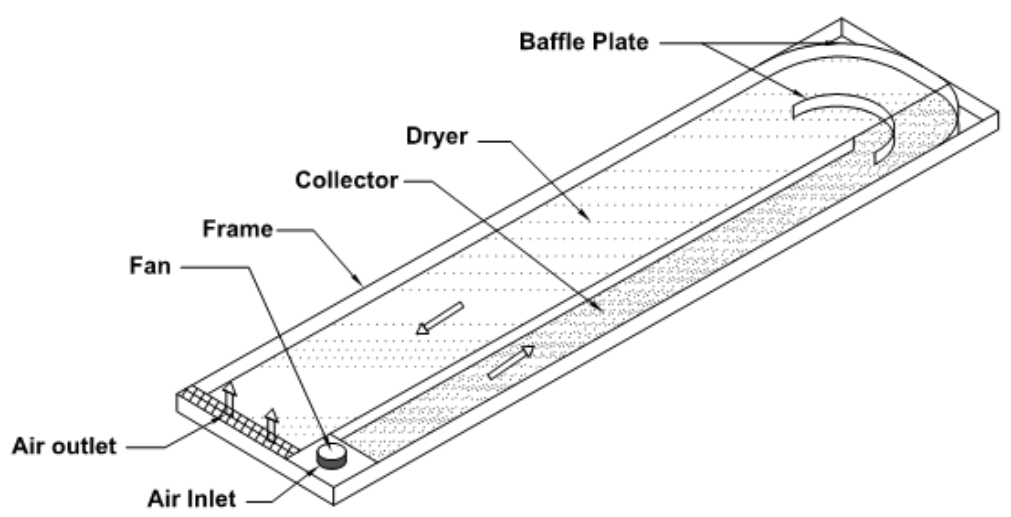

Fig. 3. Solar tunnel dryer for large quantities of agricultural products [13]

Solar tunnel dryer was experimented for drying agricultural products such as pineapple in numerous studies. An experimental study at Bangladesh Agricultural University used solar tunnel dryer with loading capacity of 120-150 kg for drying sliced pineapples. The drier used in the study 
consisted of a transparent plastic covered flat plate collector and a drying tunnel connected in a series to supply hot air directly into the drying tunnel using two dc fans operated by a solar module. The absorber outlet temperature was between $34.1^{\circ} \mathrm{C}$ to $64^{\circ} \mathrm{C}$ and the maximum solar irradiance intensity was recorded at $580 \mathrm{w} / \mathrm{m} 2$. The total fresh pineapple weight was $150 \mathrm{~kg}$, the initial and final moisture contents were $87.32 \%$ and $13.13 \%$ respectively. Total drying duration was 3 days, each day from 9 a.m. to 4 p.m. The $10 \mathrm{~mm}$ thickness of pineapple slices were treated by sulfur dioxide for 30 minutes. The researchers found out that drying time reduced considerably using solar tunnel dryer compared to sun drying $[14,15]$.

\subsection{Objective of Study}

Abundant sunshine and tropical climate of Malaysia have made pineapple a suitable fruit to be grown in this country. Plantation areas of pineapple in Malaysia have been expanded to meet the increasing demand for its products. The export value of pineapple has increased $109 \%$ by 2020 , the value raised up from RM155 million to RM320 million. Despite huge economic profit, the export of this high moisture content fruit has a significant problem [16-18].

Malaysia like other tropical countries has access to plentiful solar radiation. Solar thermal energy as a form of renewable energy has countless applications in equatorial regions. Despite the endless of solar energy sources, solar thermal energy is not fully harnessed and utilized in various sectors including but not limited to agriculture, heating system, industry, etc. Agricultural product drying for preservation has been one of the main applications of solar thermal energy for a few decades $[19,20]$. In order to dehydrate pineapple via solar thermal energy, the solar tunnel drying system is the proper method for micro-scale size to increase shelf lifetime [21].

\section{Methodology}

The active solar tunnel dryer, which was used in this experimental study, was designed, fabricated, and tested to dry sliced pineapples in the open-air solar laboratory of Solar Energy Research Institute, Universiti Kebangsaan Malaysia. The experiment latitude, longitude, and altitude are $2.5513 \mathrm{~N}, 101.4618 \mathrm{E}$ and $44 \mathrm{~m}$ above sea level respectively.

\subsection{Active Solar Tunnel Dryer (ASTD)}

The active solar tunnel dryer (ASTD) used in this study is based on indirect exposure insolation and forced convection system. The dryer structure frame is made of an aluminum extrusion profile. The ASTD dimensions are $446 \mathrm{~cm}$ long, $122 \mathrm{~cm}$ wide, and $80 \mathrm{~cm}$ height. The ASTD consists of two main sections, the head section is known as Fluid Terminal Section (FTs) and the chamber section, is known as the Drying Chamber section (DCs). The thermal absorber plate and crops bed trays are placed in the drying chamber section, solar exhaust fan, inlet vent, and transmission tube are placed in the Fluid Terminal section. Figure 4 displays the position of DCs, FTs and inlet air valves whereas, Figure 5 illustrates the inner components as well as airflow direction. The solar tunnel dryer is self-generated energy via a photovoltaic module for fan consumption. As mentioned before, the two-section of the drying system is consists of several internal and external parts, in order to clarify their application and description, Table 1 explains in detail the components. 


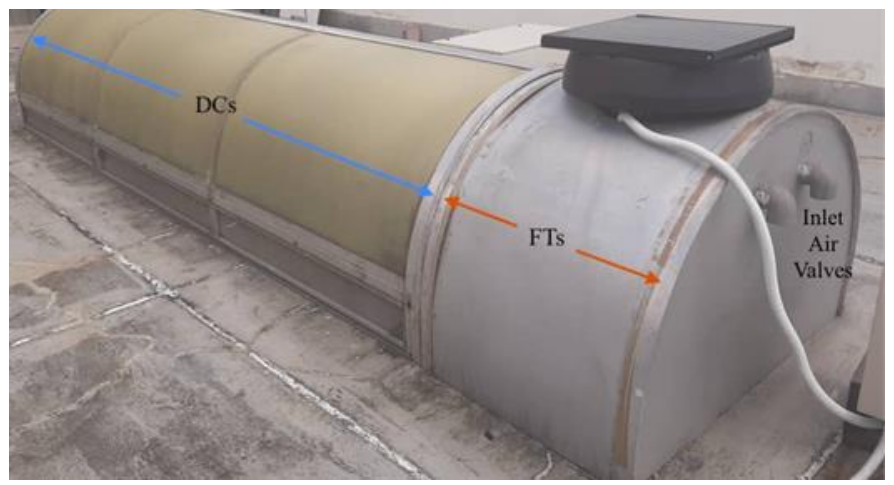

Fig. 4. Position of Fluid Terminal Section, Drying Chamber section, and inlet air valve

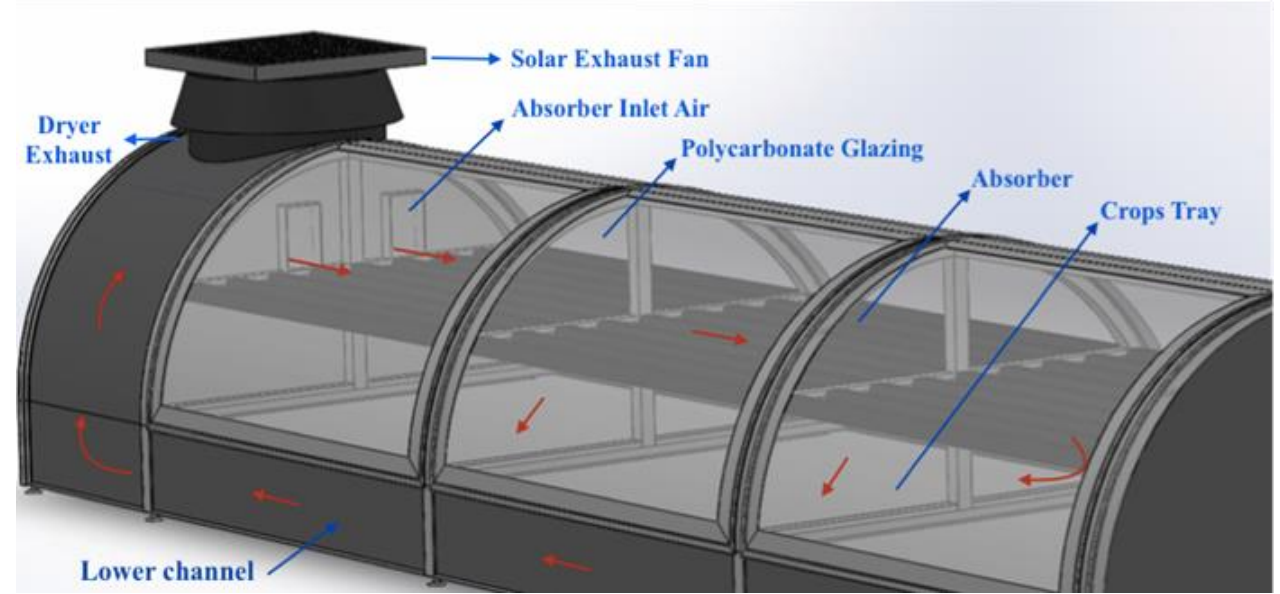

Fig. 5. Inner components and airflow direction of the solar tunnel dryer

Table 1

Component's specification

\begin{tabular}{|c|c|c|c|}
\hline No & Component Name & Application & Description \\
\hline 1 & Polycarbonate Glazing & Covering the drying chamber & Thickness: $6 \mathrm{~mm}$ \\
\hline 2 & Thermal Absorber & $\begin{array}{l}\text { Gain heat, } \\
\text { Absorb radiation }\end{array}$ & $\begin{array}{l}\text { Shape: corrugated } \\
\text { Dimensions: } 347 * 97 \mathrm{~cm} \\
\text { Material: steel } 1 \mathrm{~mm} \\
\text { Matt black color painted }\end{array}$ \\
\hline 3 & Solar Exhaust Fan & Creating airflow & $\begin{array}{l}\text { Mechanism: draw the air out } \\
\text { PV: } 40 \mathrm{~W} \text { polycrystalline } \\
\text { Fan: } 50 \mathrm{~W} \text { DC brush motor } \\
\text { Blades: } 3 \text { aluminium } \\
\text { Max tolerance: } 8.5(\mathrm{~m} / \mathrm{s})\end{array}$ \\
\hline 4 & Load Trays & Crops hold bed & $\begin{array}{l}\text { Material: aluminium } \\
\text { Shape: square, perforated } \\
\text { Dimensions: } 116^{*} 116 \mathrm{~cm} \\
\text { Quantity: } 3 p c s\end{array}$ \\
\hline 5 & Inlet Valve & Enter airflow through the dryer & $\begin{array}{l}\text { Shape: Circle } \\
\text { Dimension: } 6 \mathrm{~cm} \text { diameter } \\
\text { Quantity: } 2 \mathrm{pcs}\end{array}$ \\
\hline 6 & Transmission tube & $\begin{array}{l}\text { Transfer ambient air to absorber } \\
\text { inlet via inlet valve }\end{array}$ & $\begin{array}{l}\text { Dimensions: } 70 \mathrm{~cm} \text { length, } 6 \mathrm{~cm} \text { diameter } \\
\text { Quantity: } 2 \mathrm{pcs} \\
\text { Material: Steel }\end{array}$ \\
\hline
\end{tabular}




\subsection{Airflow Through ASTD}

ASTD is designed to absorb the solar radiation by a solar collector and use forced convection to pass the hot mass of air from solar collector into drying chamber. The solar exhaust fan creates the airflow movement in ASTD. The ambient air is pulled into inlet of absorber via inlet valve and transmission tubes. The temperature of the ambient air increases when it passes through the absorber as the absorber plates are heated by the solar radiation. As the airflow temperature goes up, its relative humidity decreases. When the heated air passes through the perforated trays, it absorbs and carries the moisture of the load to exhaust fan outlet and dehydrates the load.

\subsection{Measurement Systems}

Temperature probes; humidity meters, and irradiance intensity meter are the main data logger acquisition sensors that were used in this experimental study to collect data. Table 2 illustrates the function, location and specification of sensors function. Correct position of sensors helped to obtain more accurate data. Figure 6 displays the place of sensors and variables symbols.

Table 2

Measurement sensors specification

\begin{tabular}{|c|c|c|c|c|c|c|}
\hline Parameter & Sensor & Unit & Type & Position & Quantity & Accuracy \\
\hline $\begin{array}{l}\text { Data Logger } \\
\text { monitor- store }\end{array}$ & $\mathrm{T} / \mathrm{H} / \mathrm{G}$ & $\begin{array}{l}{ }^{\circ} \mathrm{C} / \\
\%\end{array}$ & $\begin{array}{l}\text { Midi Logger } \\
\text { GL } 820\end{array}$ & Outside Dryer & 1 & $\pm 3 \%$ \\
\hline Temperature & Thermocouple & ${ }^{\circ} \mathrm{C}$ & $\begin{array}{l}\text { K-type, } \\
-200 \text { to } \\
+1400\end{array}$ & $\begin{array}{l}\text { Inside - outside } \\
\text { Dryer }\end{array}$ & 6 & $\pm 2{ }^{\circ} \mathrm{C}$ \\
\hline R. Humidity & Hygrometer & $\%$ & B-530 & $\begin{array}{l}\text { Inside - outside } \\
\text { Dryer }\end{array}$ & 3 & $\pm 2 \sim 5 \%$ \\
\hline $\begin{array}{l}\text { Irradiance } \\
\text { intensity }\end{array}$ & Pyranometer & $\begin{array}{l}\mathrm{W} / \mathrm{M} \\
2\end{array}$ & $\begin{array}{l}\text { Apogee SP- } \\
110-\text { ss }\end{array}$ & Outside dryer & 1 & $0.2 \mathrm{mV}$ \\
\hline Air velocity & Anemometer & $\mathrm{m} / \mathrm{s}$ & $\begin{array}{l}\text { Uni-T } \\
\text { UT363BT }\end{array}$ & Inlet dryer & 1 & \pm 0.3 \\
\hline
\end{tabular}

Figure 6 demonstrate the thermocouples, hygrometers and pyranometer sensors position. The ambient air temperature and humidity are equal to absorber inlet temperature and humidity. In addition, the absorber outlet temperature and humidity are equivalent to tray area temperature and humidity.

Thermocouples position:

- $T_{a m}$ : Environmental temperature

- $T_{t t}$ : Transmission tube temperature

- $T_{i a}$ : Inlet of absorber temperature

- $T_{\text {oa: }}$ : Outlet of absorber temperature

- $T_{i t}$ : Entrance tray area temperature

- $T_{\text {ot: }}$ Outlet of tray area temperature

- Toe: Outlet of exhaust temperature

- $H_{a m}$ : Environmental humidity

- $H_{o a}$ : Entrance tray area humidity

- $H_{\text {of: }}$ Outlet of tray area humidity 


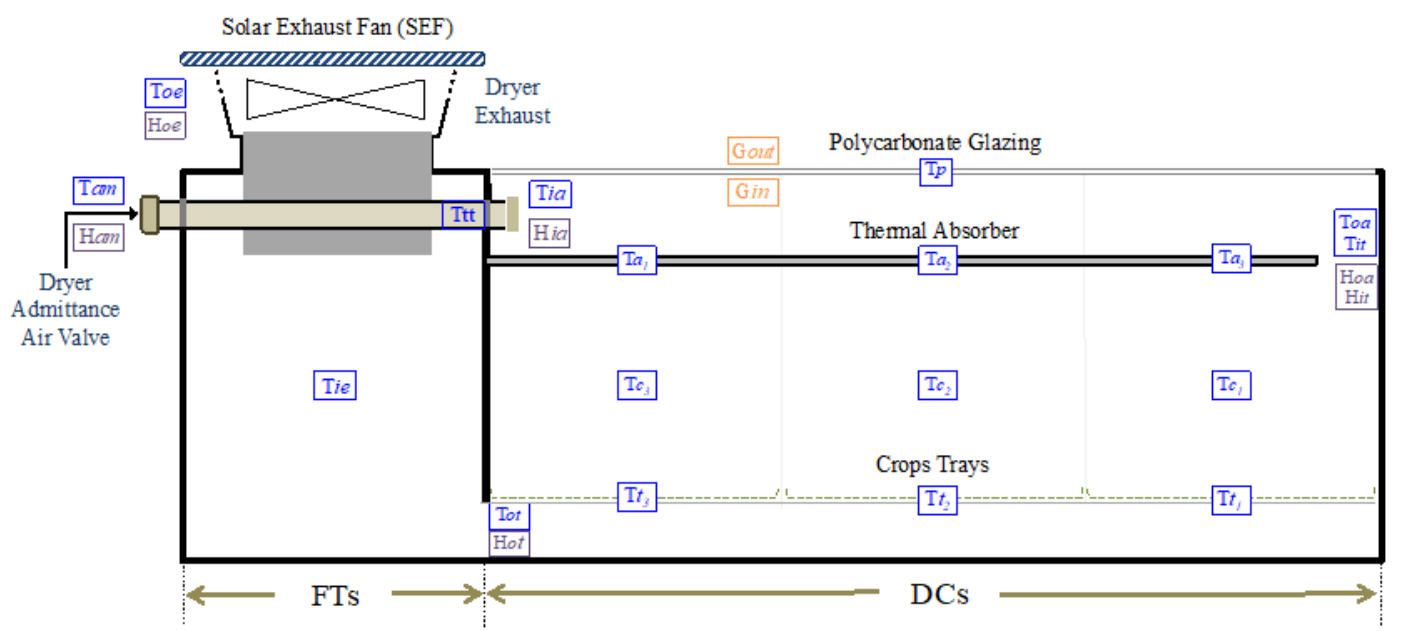

Fig. 6. The position of thermocouples, hygrometers and pyranometer sensors

\subsection{Drying Pineapple}

Pineapple has high moisture content thus drying this tropical fruit requires a reliable and capable dryer type. Active solar tunnel dryer is a suitable dryer type as it operates with solar power and due to its curvy structure has very low solar incident reflection. The experiment was conducted from 9 a.m. to 6 p.m., during which $5 \mathrm{~kg}$ of fresh pineapple were dried. Pineapples were peeled, cored, trimmed, and cut uniformly into slices with thickness of 2-3 mm (according to FAO recommendation). The sliced pineapples were placed on load trays with proper space for air circulation. There was not any pretreatment during the experiment. Figure 7(a) illustrates how sliced pineapple were arranged on load tray before the drying process whereas Figure $7(b)$ shows the dried pineapples.

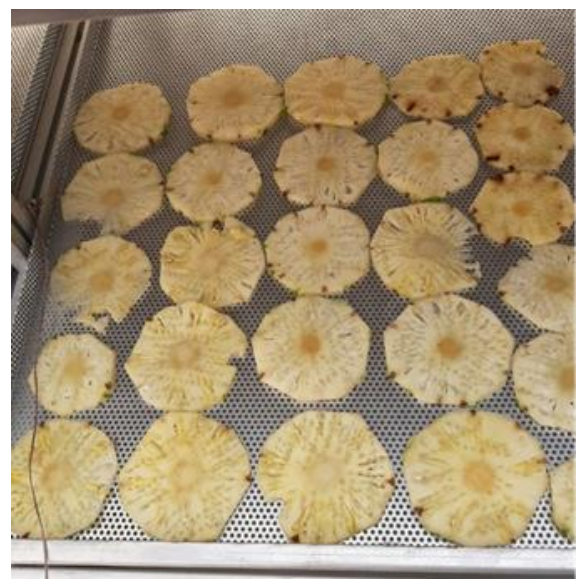

(a)

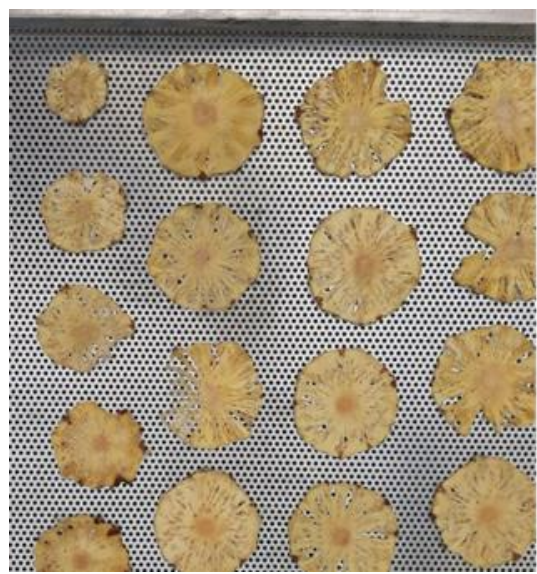

(b)

Fig. 7. Sliced pineapple arranged on tray before and after drying

\subsection{Drying Performance}

Drying efficiency $\left(\mu_{d}\right)$ is computed by using Eq. (1). The value demonstrates the ratio between amounts of energy used for drying based on evaporation over energy available from solar energy source. 
$\mu_{d}=\frac{W L}{G A_{c}}$

where $L$ : Latent heat of water evaporated, $W$ : weight of moisture evaporated, $G$ : solar insolation on collector surface and $A_{c}$ : area of collector.

Drying rate or evaporative capacity $E C$ demonstrates the capability of dryer to extract water from the drying sample within a specific period. It is determined by three parameters as shown in Eq. (2) and the unit is $\mathrm{kg} / \mathrm{h}$.

$E C=\frac{m_{i}-m_{f}}{t}$

where $t$ : Drying time, $m_{i}$ : initial weight, $m_{f}$ : final weight, $\mathrm{kg}$.

Moisture content $(\mathrm{MC})$ is one of the significant dryer's loads parameters. The MC percentage is the percent of water in crops.

$M=\frac{\left(M_{t}-M_{d}\right)}{M_{d}}$

where $m_{t}$ : Load mass at any time, $M_{d}$ : dried load mass.

Thermal efficiency shows the efficiency of the thermal absorber. Eq. (4) was used to calculate thermal energy of the absorber.

$\mu_{t h}=\frac{\dot{m} C\left(T_{i a}-T_{o a}\right)}{G A_{c}}$

where $\dot{m}$ : Mass flow rate, $C$ : specific heat of air, $T_{o a}$ : temperature of absorber outlet, $T_{i a}$ : temperature of absorber inlet, $G$ : solar insolation on collector surface, and $A_{c}$ : collector area.

An enormous number of solar drying systems have been fabricated and utilize all around the globe. In terms of load capacity, solar dryers divide into micro, medium, and industrial scale. Table 3 illustrated the specification of the solar tunnel drying system, assisted heat pump system, and open sun drying system. Among the details of the drying systems, the solar tunnel dryer is more reliable because the crops dehydrate in enclosed space, airstream uniformity, zero-cost energy, medium capital, and low maintenance. Since the solar tunnel dryer fully operates with solar energy, it is suitable for remote and sunny regions $[22,23]$. 
Table 3

Comparison solar tunnel drying system with two other drying methods

\begin{tabular}{llll} 
& \multicolumn{2}{l}{ Drying System Technologies (Micro Scale) } & \\
\cline { 2 - 4 } & Solar Tunnel Dryer & Assisted Heap Pump Drying & Open Sun drying \\
\hline $\begin{array}{l}\text { Cost of Fabrication /Cost of } \\
\text { maintenance }\end{array}$ & Medium/low & High/high & Low/low \\
Energy utilize level & low & high & low \\
Load capacity & medium & medium & high \\
Reliability/ hygiene & medium/high & High/high & Low/low \\
\hline Crops Drying Specification & & & Red chilli \\
\hline Type of Product & Pineapple & Banana & $53.7 \%$ \\
M.C Reduction $(\%)$ & $76.5 \%$ & $72 \%$ & $2-0.4$ \\
Initial - dried Weight $(\mathrm{kg})$ & $5-0.62$ & $5-0.7$ & 1.5 \\
Loading density $\left(\mathrm{kg} / \mathrm{m}^{2}\right)$ & 1.51 & 2.55 & $720 \mathrm{~m}$ \\
Drying time $(\mathrm{m})$ & $540 \mathrm{~m}$ & $235 \mathrm{~m}$ & \\
\hline
\end{tabular}

\section{Results and Discussion}

The drying process of sliced pineapples in tropical climate of Malaysia took 9 hours. The contributing factors such as relative humidity and temperature were recorded before and after the thermal absorber using a data logger. The ambient temperature or absorber inlet temperature and absorber outlet temperature trends are plotted in Figure 8 the temperature of absorber inlet ranges between $26^{\circ} \mathrm{C}$ and $38^{\circ} \mathrm{C}$ while the ranges of temperature for absorber outlet are $34^{\circ} \mathrm{C}$ to $75^{\circ} \mathrm{C}$. Table 4 shows some data regarding the load and performance of the dryer.

\section{Table 4}

Pineapple drying results

\begin{tabular}{lll}
\hline Parameter & Value & Unit \\
\hline Initial moisture & 89 & $\%$ \\
Initial weight & 5 & $\mathrm{~kg}$ \\
Final moisture & 12.5 & $\%$ \\
Dried weight & 0.62 & $\mathrm{~kg}$ \\
Drying duration & 9 & $\mathrm{~h}$ \\
Average radiation & 578 & $\mathrm{~W} / \mathrm{m}^{2}$ \\
Evaporate capacity & 0.48 & $\mathrm{Kg} / \mathrm{h}$ \\
Peak sun hours & 5.7 & $\mathrm{~h}$ \\
Loading density & 1.51 & $\mathrm{Kg} / \mathrm{m}^{2}$ \\
\hline
\end{tabular}




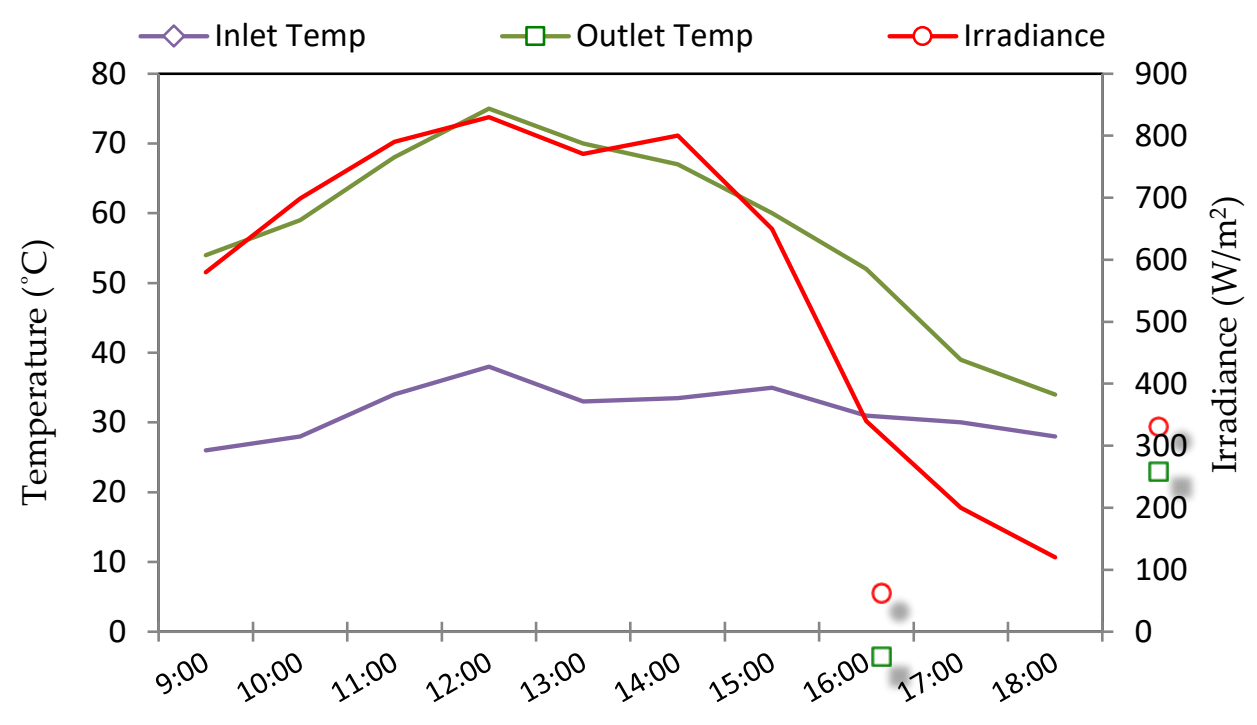

Time, $h$

Fig. 8. Variation of inlet and outlet temperature with irradiance along the experiment day

The Figure 8 shows the inlet and outlet temperature of the thermal absorber, the absorber outlet airflow quickly penetrated to drying tray area, above the crops. On the other hand, the absorber outlet temperature was equal to the drying chamber temperature. The average temperature of the drying chamber was $57.6{ }^{\circ} \mathrm{C}$. As illustrated in Figure 9 when the irradiance raised, the relative humidity decreased at 10 a.m. the inlet humidity, $31 \%$ reduced that is the highest value change.

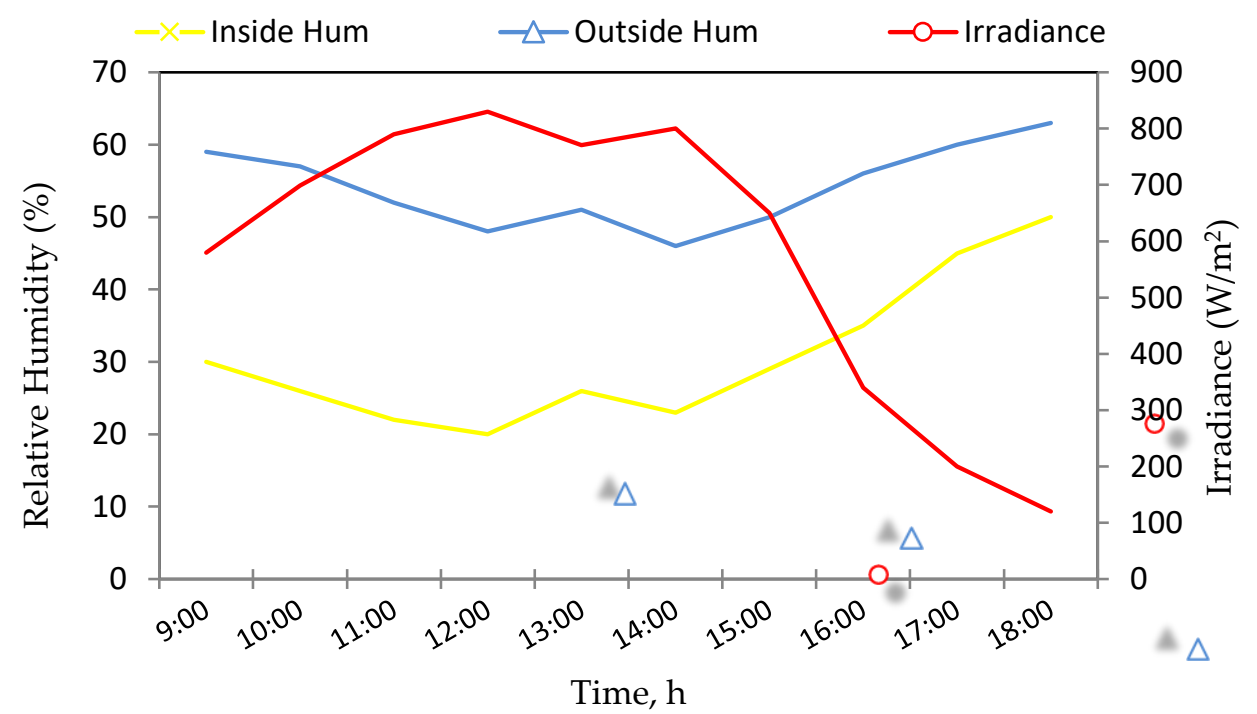

Fig. 9. Variation of relative humidity of airflow before and after heating

Sufficient airflow velocity is one of the main requirements of drying process. In ASTD the airflow velocity depends on solar irradiance intensity because the fan is powered by solar module. Figure 10 demonstrates that inlet airflow velocity and irradiance have similar patterns. 


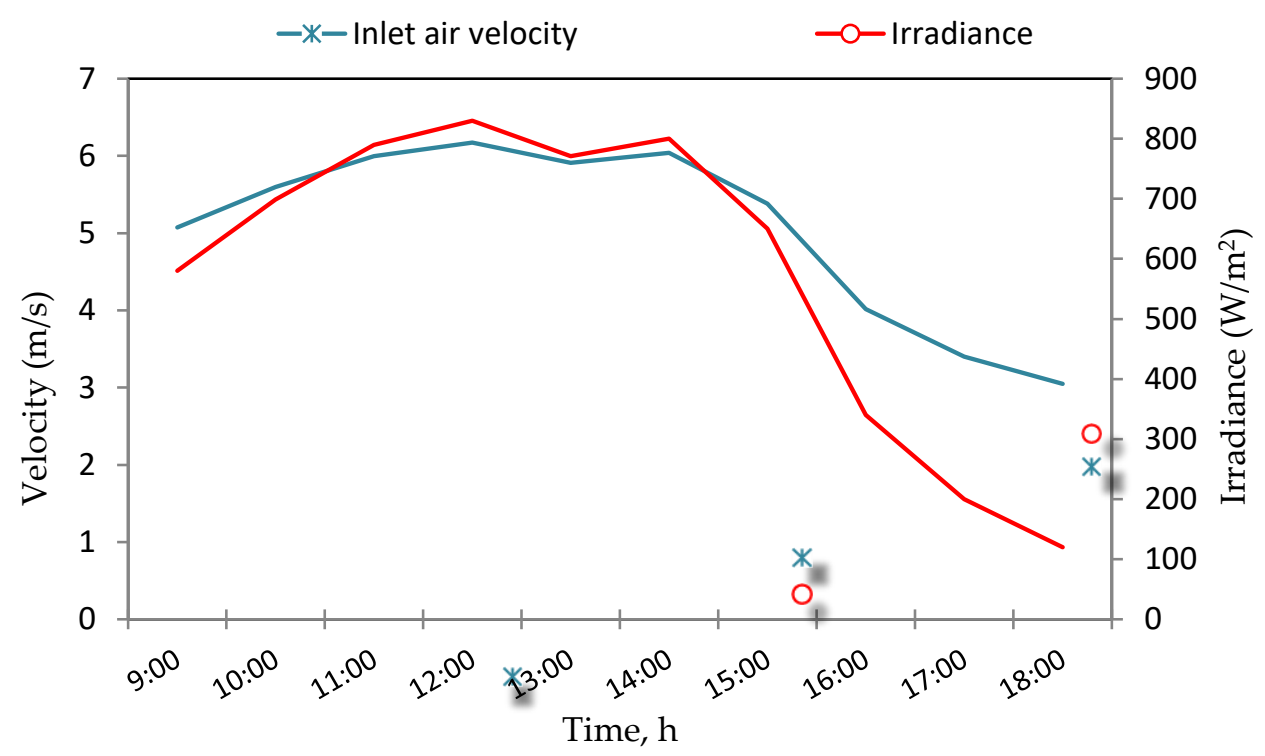

Fig. 10. Airflow variation and irradiance intensity

According to Figure 11 the minimum and maximum thermal efficiencies are $13.1 \%$ and $24.4 \%$ respectively. The thermal efficiency was obtained based on Eq. (4).

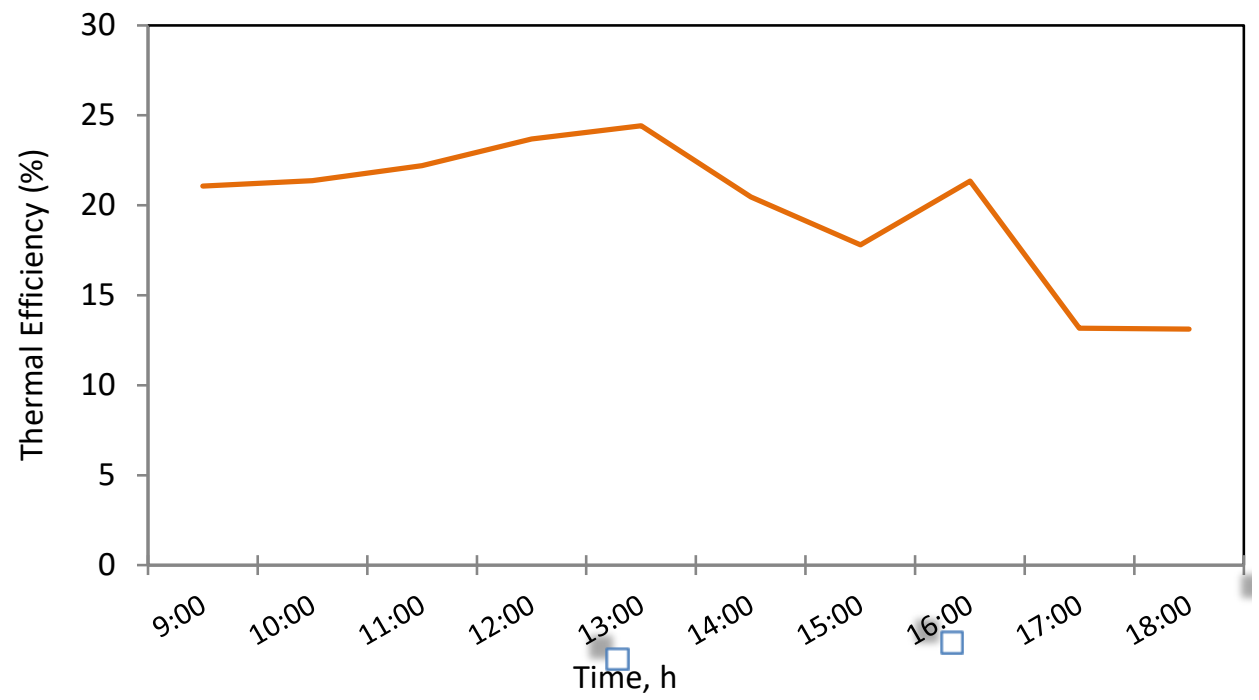

Fig. 11. Thermal efficiency of ASTD along the experiment day

Figure 12 shows the descent value of pineapple moisture content. Once the pineapple exposed to a hot stream of air, the product started to evaporate moisture and reduce weight. There is a direct relation between moisture content percentage and drying load weight. The initial moisture content of the pineapple was $89 \%$, it means $11 \%$ percent of initial pineapple weight was solid content and $89 \%$ of the initial weight of pineapple was water. The product wight carve obtain by moisture content carve. 
M.C (w.b)

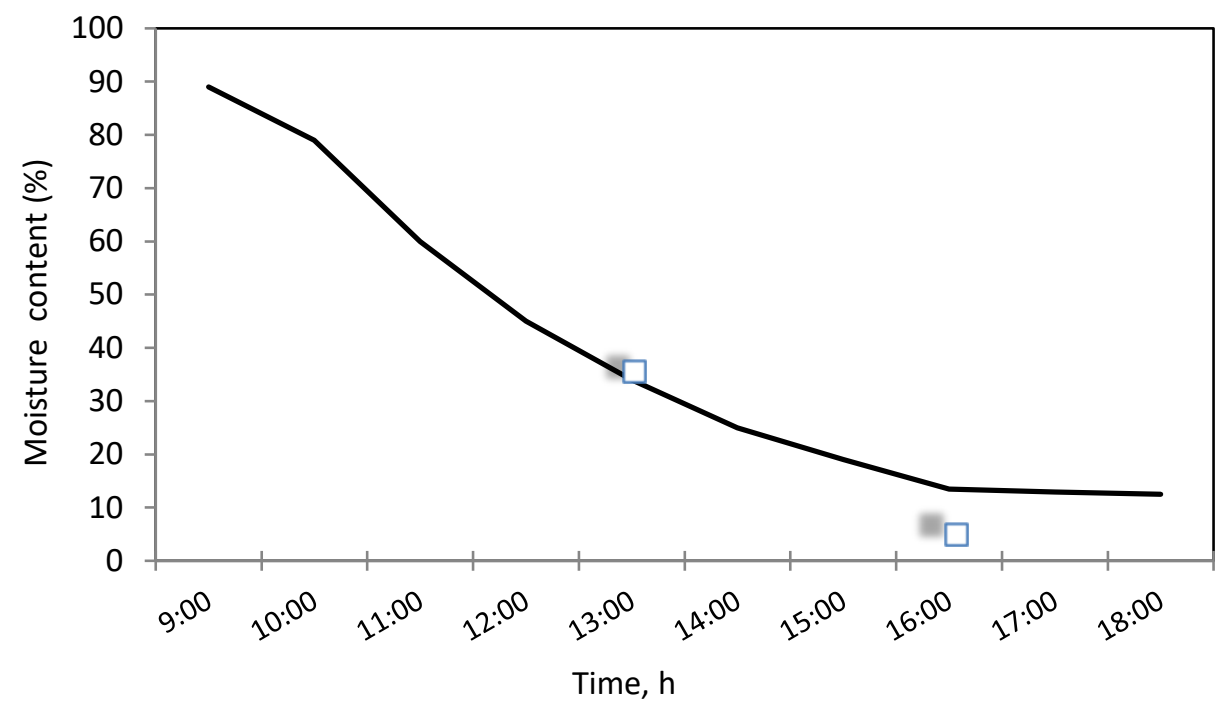

Fig. 12. Variation of pineapple moisture content

\section{Conclusions}

Active solar tunnel dryer was used in this study to dry $5 \mathrm{~kg}$ of pineapples. The quality of the dried pineapples was very high and the product was fully protected from rain, dirt, dust and other pollutants. The active solar tunnel dryer was able to extract the moisture of sliced pineapple from $89 \%$ to $12.5 \%$ within 9 hours. The solar irradiance peak was $830(\mathrm{~W} / \mathrm{m} 2)$ at 12 p.m. with the average of $578 \mathrm{~W} / \mathrm{m} 2$ and the PSH was 5.7. The maximum and minimum temperature difference between absorber outlet and inlet was $37^{\circ} \mathrm{C}$ and $36^{\circ} \mathrm{C}$ which occurred at 12 p.m. and 6 p.m. The ambient or absorber inlet relative humidity ranged between $46 \%$ to $63 \%$ and the outlet of absorber ranged between $20 \%$ to $50 \%$. Results proved that drying rate was high and active solar tunnel dryer is a suitable type of dryer for drying pineapples in tropical regions.

\section{Acknowledgement}

The authors wish to express the earnest appreciation to Ministry of Higher Education Malaysia for the funding through MRUN-RAKAN RU-2019-001/1.

\section{References}

[1] Ssemwanga, M., E. Makule, and S. I. Kayondo. "Performance analysis of an improved solar dryer integrated with multiple metallic solar concentrators for drying fruits." Solar Energy 204 (2020): 419-428. https://doi.org/10.1016/i.solener.2020.04.065

[2] César, López-Vidaña Erick, César-Munguía Ana Lilia, García-Valladares Octavio, Pilatowsky Figueroa Isaac, and Brito Orosco Rogelio. "Thermal performance of a passive, mixed-type solar dryer for tomato slices (Solanum lycopersicum)." Renewable Energy 147 (2020): 845-855. https://doi.org/10.1016/i.renene.2019.09.018

[3] Devan, P. K., Chidambaranathan Bibin, I. Asburris Shabrin, R. Gokulnath, and D. Karthick. "Solar drying of fruits-A comprehensive review." Materials Today: Proceedings (2020). https://doi.org/10.1016/i.matpr.2020.04.041

[4] Udomkun, Patchimaporn, Sebastian Romuli, Steffen Schock, Busarakorn Mahayothee, Murat Sartas, Tesfamicheal Wossen, Emmanuel Njukwe, Bernard Vanlauwe, and Joachim Müller. "Review of solar dryers for agricultural products in Asia and Africa: An innovation landscape approach." Journal of Environmental Management 268 (2020): 110730. https://doi.org/10.1016/i.jenvman.2020.110730

[5] Eltawil, Mohamed A., Mostafa M. Azam, and Abdulrahman O. Alghannam. "Energy analysis of hybrid solar tunnel dryer with PV system and solar collector for drying mint (MenthaViridis)." Journal of Cleaner Production 181 (2018): 352-364. https://doi.org/10.1016/j.jclepro.2018.01.229 
[6] Lingayat, Abhay Bhanudas, V. P. Chandramohan, V. R. K. Raju, and Venkatesh Meda. "A review on indirect type solar dryers for agricultural crops-Dryer setup, its performance, energy storage and important highlights." Applied Energy 258 (2020): 114005. https://doi.org/10.1016/i.apenergy.2019.114005

[7] Rajkumar, P., S. Kulanthaisami, G. S. V. Raghavan, Y. Gariépy, and V. Orsat. "Drying kinetics of tomato slices in vacuum assisted solar and open sun drying methods." Drying Technology 25, no. 7-8 (2007): 1349-1357. https://doi.org/10.1080/07373930701438931

[8] Phadke, Pranav C., Pramod V. Walke, and Vilayatrai M. Kriplani. "A review on indirect solar dryers." ARPN Journal of Engineering and Applied Sciences 10, no. 8 (2015): 3360-3371.

[9] Sharma, Atul, C. R. Chen, and Nguyen Vu Lan. "Solar-energy drying systems: A review." Renewable and sustainable energy reviews 13, no. 6-7 (2009): 1185-1210. https://doi.org/10.1016/i.rser.2008.08.015

[10] Sacilik, Kamil, Rahmi Keskin, and Ahmet Konuralp Elicin. "Mathematical modelling of solar tunnel drying of thin layer organic tomato." Journal of food Engineering 73, no. $3 \quad$ (2006): $231-238$. https://doi.org/10.1016/i.jfoodeng.2005.01.025

[11] Patil, Rajendra, and Rupesh Gawande. "A review on solar tunnel greenhouse drying system." Renewable and sustainable energy reviews 56 (2016): 196-214. https://doi.org/10.1016/i.rser.2015.11.057

[12] Ragul Kumar, N., Muthukkannan Natarajan, S. Ayyappan, and Karunaraja Natarajan. "Analysis of Solar Tunnel Dryer Performance with Red Chili drying in two intervals.

[13] Patil, Rajendra, and Rupesh Gawande. "A review on solar tunnel greenhouse drying system." Renewable and sustainable energy reviews 56 (2016): 196-214. https://doi.org/10.1016/j.rser.2015.11.057

[14] Bala, B. K., M. R. A. Mondol, B. K. Biswas, BL Das Chowdury, and S. Janjai. "Solar drying of pineapple using solar tunnel drier." Renewable Energy 28, no. 2 (2003): 183-190. https://doi.org/10.1016/S0960-1481(02)00034-4

[15] Rathore, N. S., and N. L. Panwar. "Experimental studies on hemi cylindrical walk-in type solar tunnel dryer for grape drying." Applied Energy 87, no. 8 (2010): 2764-2767. https://doi.org/10.1016/i.apenergy.2010.03.014

[16] Salleh, N. F. M., E. H. Sukadarin, N. K. Khamis, and R. Ramli. "Pattern of muscle contraction in different postures among Malaysia pineapple plantation workers." In IOP Conference Series: Materials Science and Engineering, (2019): vol. 469, no. 1, p. 012088. IOP Publishing. https://doi.org/10.1088/1757-899X/469/1/012088

[17] Nunti, Chonrada, Kewalin Somboon, and Chanamart Intapan. "The Impact of Climate Change on Agriculture Sector in ASEAN." In Journal of Physics: Conference Series, (2020): vol. 1651, no. 1, p. 012026. IOP Publishing. https://doi.org/10.1088/1742-6596/1651/1/012026

[18] Bakri, Mohd Azwan Mohd, J. Salmah, S. Abd Rahim, and K. Norman. "A study on Agro-Hybrid Farm Vehicle with Small Onboard Solar Photovoltaic for Herbicide Spraying in Oil Palm Plantation (2019).

[19] Tunçkal, Cüneyt, Salih Coşkun, and Ibrahim Doymaz. "Determination of sliced pineapple drying characteristics in a closed loop heat pump assisted drying system." International Journal of Renewable Energy Development 7, no. 1 (2018): 35. https://doi.org/10.14710/ijred.7.1.35-41

[20] Lubis, Hamzah. "Renewable Energy of Rice Husk for Reducing Fossil Energy in Indonesia." Journal of Advanced Research in Applied Sciences and Engineering Technology 11, no. 1 (2018): 17-22.

[21] PNRJ, Amunugoda, Senanayake NS, Wilson Wijeratnam RS, and Kulatunga KDG. "Quality Enhancement of Dehydrated Products through the Modification of Solar Tunnel Dryer for Continuous Operation in Rural Communities." (2020).

[22] Singh, Akhilesh, Jahar Sarkar, and Rashmi Rekha Sahoo. "Experimentation on solar-assisted heat pump dryer: Thermodynamic, economic and exergoeconomic assessments." Solar Energy 208 (2020): 150-159. https://doi.org/10.1016/i.solener.2020.07.081

[23] Pochont, Nitin Ralph, Mohammad Noor Mohammad, Bodepu Thrinadh Pradeep, and P. Vijaya Kumar. "A comparative study of drying kinetics and quality of Indian red chilli in solar hybrid greenhouse drying and open sun drying." Materials Today: Proceedings 21 (2020): 286-290. https://doi.org/10.1016/i.matpr.2019.05.433 